\title{
Detección de Treponema pallidum subespecie pallidum para el diagnóstico de sífilis congénita mediante reacción en cadena de la polimerasa anidada
}

\author{
Gladys Pinilla, Lesly Campos, Andrea Durán, Jeannette Navarrete, Liliana Muñoz \\ Grupo de Investigación REMA, Facultad de Ciencias de la Salud, Programa de Bacteriología y \\ Laboratorio Clínico, Universidad Colegio Mayor de Cundinamarca, Bogotá, D.C., Colombia
}

Introducción. La sífilis es una enfermedad producida por Treponema pallidum subespecie pallidum cuya incidencia mundial es de 12 millones de casos por año, aproximadamente; de estos, más de dos millones se presentan en mujeres gestantes, siendo la sífilis congénita la complicación más grave de esta infección en el embarazo.

Objetivo. Detectar la presencia de T. pallidum subespecie pallidum en muestras clínicas para el diagnóstico de sífilis congénita mediante reacción en cadena de la polimerasa (PCR) anidada y determinar su concordancia con las pruebas serológicas.

Materiales y métodos. Mediante PCR convencional y anidada, se amplificaron tres genes diana (polA, 16S ADNry TpN47) y se confirmaron los productos de amplificación de los genes TpN47 y polA por secuenciación. Las pruebas serológicas empleadas fueron la VDRL (Venereal Disease Research Laboratory), la de reagina plasmática rápida (Rapid Plasma Reagin, RPR) y la de aglutinación de partículas para Treponema pallidum (Treponema pallidum Particle Agglutination Assay, TPPA).

Resultados. La sensibilidad para la PCR convencional fue de $52 \mathrm{pg}$ y, para la PCR anidada, de 0,52 pg. La especificidad con los iniciadores TpN47 y polA fue de $100 \%$; los resultados de la secuenciación mostraron una identidad de $97 \%$ con T. pallidum. En $70 \%$ de las muestras, los resultados de las pruebas serológicas y la PCR anidada concordaron.

Conclusión. El gen TpN47 resultó ser el mejor blanco molecular para la identificación de $T$. pallidum. La PCR anidada se presenta como una alternativa de diagnóstico molecular promisoria para el diagnóstico de sífilis congénita.

Palabras clave: Treponema pallidum; sífilis congénita; reacción en cadena de la polimerasa; serología. doi: https://doi.org/10.7705/biomedica.v38i0.3740

Detection of Treponema pallidum subspecies pallidum for the diagnosis of congenital syphilis by nested polymerase chain reaction

Introduction. Syphilis is a disease produced by Treponema pallidum subspecies pallidum, which affects approximately 12 million people worldwide every year. Of these, more than 2 million are pregnant women whose babies end up having congenital syphilis, the worst form of this infection.

Objective. To detect the presence of $T$. pallidum subspecies pallidum in clinical samples in order to diagnose congenital syphilis by means of nested PCR, and to determine its concordance with serological testing.

Materials and methods. Three target genes ( $p o / A, 16 S$ ADNry TpN47) were amplified by conventional and nested PCR. The results from the amplification of the TpN47 and polA genes were confirmed by sequencing. The serological tests used were VDRL (Venereal Disease Research Laboratory), RPR (Rapid Plasma Reagin) y TPPA (Treponema pallidum Particle Agglutination Assay).

Results. The sensitivity for the conventional PCR was $52 \mathrm{pg}$ and $0.52 \mathrm{pg}$ for the nested PCR. The specificity of primers $T p N 47$ and polA was $100 \%$; the results of the sequencing showed a $97 \%$ identity with T. pallidum. There was concordance between the serology and the nested PCR in $70 \%$ of the samples. Conclusion. The TpN47 gene was the best molecular target for the identification of $T$. pallidum. The nested PCR is a promising molecular tool for the diagnosis of congenital syphilis.

Key words: Treponema pallidum; syphilis, congenital; polymerase chain reaction; serology. doi: https://doi.org/10.7705/biomedica.v38i0.3740

\section{Contribución de los autores:}

Gladys Pinilla: planificación del proyecto, asesoría y seguimiento de la investigación

Lesly Campos y Andrea Durán: revisión bibliográfica, pruebas moleculares y análisis de resultados

Jeannette Navarrete y Liliana Muñoz: pruebas serológicas, análisis de resultados y seguimiento de la investigación

Todas las autoras participaron en la escritura del manuscrito. 
La sífilis es una infección de transmisión sexual causada por la espiroqueta Treponema pallidum subespecie pallidum (1). Entre 0,5 y 1,0 millón de casos de sífilis congénita se producen en el mundo cada año y más de una quinta parte de los casos de mortalidad neonatal se atribuyen directamente a la sífilis en algunos países en desarrollo (2), en donde el $10 \%$ de la población puede estar infectada (3).

Según reportes de Instituto Nacional de Salud, en la década del 2000 al 2010, la prevalencia de sífilis congénita en Colombia pasó de 1,3 a 2,5 por mil nacidos vivos, y la de la gestacional, de 1,3 a 5,4. Además, el subregistro de casos es elevado, por lo cual no se conoce la verdadera magnitud del problema (4). Solo en el litoral pacífico colombiano, se reportaron 141 casos de sífilis congénita en el 2010, y su incidencia a nivel nacional fue de 1,68, 1,04 y 0,55 en 2014,2015 y 2016 , respectivamente (5-7). La sífilis gestacional y la congénita se consideran un problema de salud pública, por lo cual se planteó un "Plan estratégico para la eliminación de la transmisión materno-infantil de VIH y de la sífilis congénita, 2011-2015", así como una nueva guía de práctica clínica basada en la 'evidencia' (8-10).

Cuando la sífilis se presenta en el embarazo, se asocia con pronósticos devastadores en la mayoría de los casos, incluidos la pérdida temprana del feto, la muerte fetal, el parto prematuro, el bajo peso al nacer, la muerte neonatal e infantil y las enfermedades congénitas en los recién nacidos (2). La detección temprana es crucial para la prevención de estas complicaciones (11), pero hay dificultades en el diagnóstico debido a que, en los países en desarrollo, las mujeres embarazadas no siempre tienen acceso a los controles prenatales $(11,12)$. Además, las técnicas serológicas no tienen especificidad suficiente para la detección de la enfermedad en los neonatos y su sensibilidad también es baja, por lo que se pueden presentar falsos positivos o falsos negativos, y los métodos diagnósticos no están ampliamente disponibles $(1,2,13)$.

\footnotetext{
Correspondencia:

Gladys Pinilla, Facultad de Ciencias de la Salud, Programa de Bacteriología y Laboratorio Clínico, Universidad Colegio Mayor de Cundinamarca, Calle 28 N 5B-02, Bogotá, D.C., Colombia Teléfono: (571) 241 8800, extensión 281; fax: (571) 2841717 gpinillab@unicolmayor.edu.co y gpinillab@gmail.com

Recibido: 15/12/16; aceptado: 27/03/17
}

Treponema pallidum es una espiroqueta no cultivable en medios artificiales; por tal motivo, en el diagnóstico de laboratorio se utiliza la microscopía de campo oscuro o las pruebas serológicas, cuyos resultados pueden verse alterados por diversas situaciones propias del paciente o de la técnica. Asimismo, el diagnóstico de la sífilis congénita se complica debido a que $60 \%$ de los niños infectados son asintomáticos al nacer, o presentan signos leves e inespecíficos (14).

Por otro lado, la detección molecular del microorganismo se ha implementado para el diagnóstico oportuno de la sífilis, la tipificación de las cepas y la evaluación de la resistencia antimicrobiana (15). Con la PCR se puede detectar el agente patógeno directamente, su tiempo de reacción es corto, su rendimiento es bueno y puede evitar falsos negativos en el diagnóstico de la sífilis; la técnica, además, puede hacerse en la mayoría de los laboratorios microbiológicos actuales (16).

La variante anidada de la PCR consiste en la amplificación de una parte del producto de una reacción realizada con anterioridad. La amplificación mediante PCR de una región del gen polA se ha utilizado preferentemente para la detección de casos sospechosos de sífilis (2), ya que su secuencia está muy conservada en los diversos organismos. También, se suele emplear el gen $T p N 47$, el cual codifica una proteína integral de membrana y es inmunógeno dominante de $T$. pallidum $(17,18)$. El gen $16 S A R N r$, cuya ventaja es el gran número de copias por célula, también se ha utilizado para detectar especies bacterianas mediante PCR.

En este contexto, se vio la necesidad de seleccionar un gen blanco para el diagnóstico efectivo e implementar una técnica sensible y específica para la detección temprana de los neonatos y de las mujeres gestantes infectadas, con el fin de garantizar su tratamiento, así como el control y la vigilancia oportunos.

\section{Materiales y métodos}

\section{Muestras infectadas en el laboratorio}

Se inocularon 25, 50 y $100 \mu \mathrm{l}$ de exudado de testículo de conejo infectado con $T$. pallidum en muestras negativas de sangre y tejido de cordón umbilical.

\section{Muestras clínicas}

Se procesaron 15 muestras de suero, siete de líquido cefalorraquídeo (LCR) de hijos y una de sangre de cordón umbilical, provenientes de madres e hijos con sospecha de sífilis gestacional 
y congénita. Como control positivo, se usó exudado de testículo de conejos infectados con la cepa de control Nichols de la bacteria T. pallidum subespecie pallidum (donada por el Departamento de Inmunopatología de la Sífilis, Universidad de Washington, Seattle, Estados Unidos). Como controles negativos, se usaron muestras de suero de pacientes que habían sido analizadas mediante pruebas treponémicas y no treponémicas, y cuyos resultados fueron negativos.

\section{Extracción de ADN}

En las muestras infectadas en el laboratorio, las muestras clínicas de suero, las de sangre de cordón y las de control, se aplicó un tratamiento previo con proteinasa $\mathrm{K}(2 \mathrm{mg} / \mathrm{ml})$ a $65{ }^{\circ} \mathrm{C}$ durante una hora con una solución tampón de lisis celular o nuclear, según el caso, y se siguieron las indicaciones del estuche Genomic DNA Purification ${ }^{\circledR}$ (Promega) $(19,20)$. Las muestras de líquido cefalorraquídeo se trataron con proteinasa $\mathrm{K}(4 \mathrm{mg} / \mathrm{ml})$ y se incubaron durante 20 minutos a $65^{\circ} \mathrm{C}$, utilizando el protocolo de extracción del estuche QIAamp DNA Minikit ${ }^{\circledR}$ (QIAGEN) (21).

\section{PCR convencional}

Se amplificaron las secuencias de los genes polA, $16 S$ ADNr y TpN47 de $T$. pallidum subespecie pallidum, a partir de ADN de control positivo utilizando los iniciadores diseñados y las condiciones previamente descritas por Pinilla, et al. (20).

\section{PCR anidada}

Los productos de amplificación obtenidos por PCR convencional, se amplificaron nuevamente mediante una segunda pareja de iniciadores internos (polA-2, 16S-2 y TpN47-2) descritos previamente (20). Se tomó $1 \mu \mathrm{l}$ del producto de amplificación de la PCR convencional.

\section{Ensayo de sensibilidad y especificidad}

Se hicieron 10 diluciones seriadas en base 10 del ADN de control positivo (2,6 ng/ $\mu$ l) y, para determinar la especificidad, se usó ADN de Salmonella enteritidis, Enterobacter aerogenes, Klebsiella pneumoniae, Proteus mirabilis y ADN humano extraído de sangre de pacientes sanos.

\section{Muestras infectadas en el laboratorio y muestras clínicas}

Se seleccionaron las secuencias de los genes TpN47 y polA por ser los más específicos y se amplificaron mediante PCR anidada a partir de muestras de sangre y tejido de cordón umbilical infectadas en el laboratorio. En las muestras clínicas, se amplificó el gen TpN47 por ser el blanco molecular que mostró mejores resultados en las pruebas preliminares.

\section{Secuenciación}

Se llevó a cabo la secuenciación del amplicón de los genes polA (200 pb) y TpN47 (135 pb) (22), y con las herramientas Blast y Chromas, se analizaron las secuencias obtenidas.

\section{Pruebas serológicas}

Se utilizaron las pruebas TPPA (treponémica) y VDRL y RPR (no treponémicas), para las muestras de suero de madres y neonatos, y de líquido cefalorraquídeo de neonatos (23-25).

\section{Resultados}

\section{Sensibilidad de la PCR convencional y la PCR anidada}

Con la PCR convencional se obtuvo una sensibilidad de $52 \mathrm{pg}$, usando como gen blanco el $T p N 47$, en tanto que, con la PCR anidada, se alcanzó una sensibilidad de 0,52 pg, es decir, la sensibilidad aumentó 100 veces con este último en comparación con el primero.

El gen $16 S$ ADNr se comportó de forma similar, con un aumento de 1.000 veces en la sensibilidad al amplificar de nuevo el producto.

El gen polA mostró ser el blanco con menor sensibilidad, pues permitió identificar 52 pg de ADN en la PCR anidada (cuadro 1).

\section{Especificidad}

Se encontró una especificidad de $100 \%$ en los iniciadores $T p N 47$ y polA, ya que no hubo amplificación de ninguna cadena de molde de ADN bacteriano o humano. Por el contrario, los iniciadores de $16 S \mathrm{ADNr}$ demostraron ser inespecíficos al

Cuadro 1. Sensibilidad de los blancos moleculares en la PCR anidada

\begin{tabular}{lccc}
\hline Sensibilidad & TpN47 & polA & 16S ADNr \\
\hline En la PCR-1 & 52 pg de ADN & 520 pg de ADN & 520 pg de ADN \\
En la PCR-2 & 0,52 pg de ADN & 52 pg de ADN & 0,52 pg de ADN \\
\hline
\end{tabular}


usar como cadena de molde de las reacciones el ADN de $E$. aerogenes y $P$. mirabilis, por lo cual registraron una especificidad de $60 \%$; estos hallazgos solo se hicieron evidentes en la segunda ronda de amplificación.

\section{Muestras infectadas en el laboratorio}

Se logró la amplificación de las muestras experimentalmente infectadas en el laboratorio usando el gen TpN47; los amplicones fueron observables desde la primera amplificación. Sin embargo, en muestras clínicas es importante hacer la PCR anidada, ya que la muestra clínica 01 de líquido cefalorraquídeo solo fue positiva a partir de la segunda ronda de amplificación, en tanto que, al usar el gen polA como blanco molecular, solo dos muestras experimentalmente infectadas en el laboratorio amplificaron y fueron positivas en la segunda ronda de PCR (figura 1).

\section{Concordancia entre las pruebas serológicas y las pruebas moleculares}

Se procesaron 23 muestras clínicas mediante PCR anidada y, en 20 de ellas, se hicieron también las pruebas serológicas. En 14 de las muestras se obtuvieron resultados concordantes con los dos tipos de pruebas (70\%): 11 de ellas correspondían a muestras clínicas con resultados positivos con ambas técnicas (55\%) y en tres los resultados fueron negativos (15\%) (cuadro 2).

Se evidenció una concordancia de 42,8 \% entre las pruebas moleculares y la prueba de TPPA en seis de las 14 muestras analizadas, y hubo resultados discrepantes en seis de las muestras (30\%) procesadas con las dos técnicas: una (5\%) muestra fue positiva en la PCR anidada y negativa en las pruebas serológicas, y cinco (25\%) muestras fueron positivas en la serología y negativas en la PCR anidada. Se obtuvieron resultados positivos en $16(80 \%)$ muestras con serología y en 12 (60\%) con la PCR anidada (cuadro 3).

\section{Secuenciación}

Se obtuvo una identidad de $97 \%$ con las secuencias de la base de datos Blast de T. pallidum subespecie pallidum, lo cual confirmó que, en las reacciones de PCR anidada, se amplificaron efectivamente los genes $T p N 47$ y polA del microorganismo; así, se ratificó la confiabilidad de la amplificación del ADN de la espiroqueta en las muestras clínicas.

\section{Discusión}

Una de las enfermedades más antiguas conocidas es la sífilis, la cual sigue causando una gran morbimortalidad perinatal $(4,26)$, situación que requiere una intervención para alcanzar los objetivos de los planes de salud reproductiva a nivel nacional y mundial (27).

Para determinar los genes de T. pallidum subespecie pallidum, se han empleado diversos métodos de PCR. En este estudio se emplearon la PCR convencional y la PCR anidada en los genes $p o l A, T p N 47 y$ $16 S A D N r$, para identificar el microorganismo.

La PCR y sus variantes, la PCR anidada, la PCR de transcripción inversa y la PCR cuantitativa, se han utilizado para amplificar, entre otros, los genes
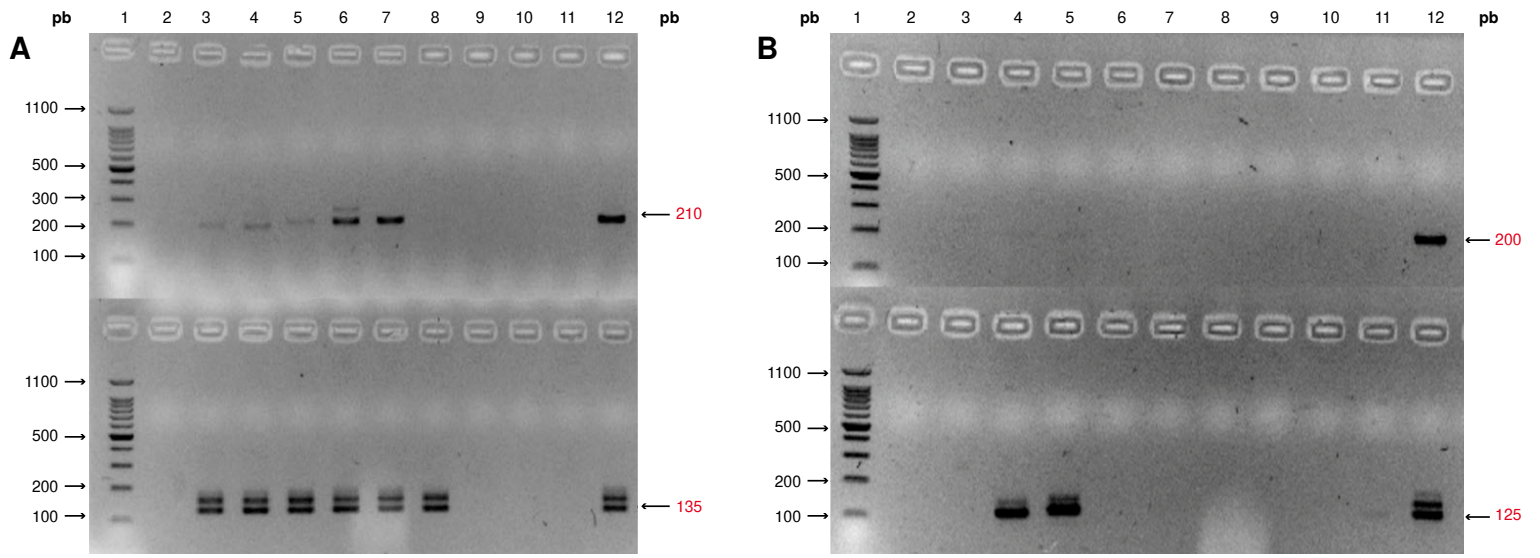

Figura 1. Electroforesis en gel de agarosa de productos de amplificación de la PCR anidada usando los genes $T p N 47$ (A) y polA (B) Parte superior: productos de la primera PCR con los iniciadores TpN47-1 (A) y polA-1 (B). Parte inferior: productos de la PCR anidada con los iniciadores TpN47-2 (A) y polA-2 (B).

Carril 1: marcador de peso molecular de 100 pb. Carril 2: control negativo. Carriles 3 a 7: muestras experimentalmente infectadas. Carril 8: muestra clínica de líquido cefalorraquídeo de neonato número 01. Carril 10: muestra clínica de líquido cefalorraquídeo de neonato número 03. Carril 11: muestra clínica de suero de neonato. Carril 12: control positivo, ADN de T. pallidum 
Cuadro 2. Concordancia entre los resultados obtenidos mediante la PCR anidada y las pruebas serológicas, según el tipo de muestra

\begin{tabular}{|c|c|c|c|c|c|c|}
\hline \multirow[t]{2}{*}{ Tipo de muestra } & \multicolumn{2}{|c|}{$\begin{array}{l}\text { PCR anidada positiva y } \\
\text { serología positiva }\end{array}$} & \multicolumn{2}{|c|}{$\begin{array}{l}\text { PCR anidada negativa y } \\
\text { serología negativa }\end{array}$} & \multicolumn{2}{|c|}{ Total } \\
\hline & $\mathbf{n}$ & $\%$ & $\mathbf{n}$ & $\%$ & $\mathbf{n}$ & $\%$ \\
\hline Suero & $10 / 15$ & 66,6 & $1 / 15$ & 6,6 & $11 / 15$ & 73,3 \\
\hline LCR & $0 / 4$ & 0 & $2 / 4$ & 50 & $2 / 4$ & 50 \\
\hline Sangre de cordón umbilical & $1 / 1$ & 100 & $0 / 1$ & 0 & $1 / 1$ & 100 \\
\hline Total & $11 / 20$ & 55 & $3 / 20$ & 15 & $14^{*} / 20$ & 70 \\
\hline
\end{tabular}

* Total de muestras con resultados concordantes en la PCR anidada y en las pruebas serológicas. LCR: líquido cefalorraquídeo

Cuadro 3. Muestras con resultados discrepantes en la PCR anidada y en las pruebas serológicos

\begin{tabular}{lcccccc}
\hline Muestras discrepantes & \multicolumn{2}{c}{ PCR anidada positiva } & \multicolumn{2}{c}{ PCR anidada negativa } & \multicolumn{2}{c}{ Total } \\
\cline { 2 - 7 } & $\mathbf{n}$ & $\%$ & $\mathbf{n}$ & $\%$ & $\mathbf{n}$ & $\%$ \\
\hline Serología positiva & $11 / 20$ & 55 & $5 / 20$ & 25 & $16 / 20$ & 80 \\
Serología negativa & $1 / 20$ & 5 & $3 / 20$ & 15 & $4 / 20$ & 20 \\
Total & $12 / 20$ & 60 & $8 / 20$ & 40 & $20 * / 20$ & 100 \\
\hline
\end{tabular}

* Total de muestras procesadas mediante PCR anidada y pruebas serológicas

BMP, TpN47, TMPA y 4D (1), los cuales codifican para proteínas de superficie. Asimismo, se ha usado el gen polA, involucrado en la duplicación del genoma, y los genes $16 S A D N r$ y $23 S A D N r$, que codifican el ARN ribosómico de $T$. pallidum $(2,16,17,28-30)$.

El gen $T p N 47$ codifica la lipoproteína de 47 kDa y es uno de los objetivos más comúnmente reportados en PCR. Algunos autores plantean la hipótesis de que la proteína puede estar implicada en la síntesis de la pared celular y sería de esperar que este antígeno se conserve en espiroquetas relacionadas. Sin embargo, su función exacta no está clara, por lo cual la optimización de los cebadores es difícil debido a que las secuencias homólogas no están disponibles para la comparación (31).

El gen polA, que codifica para la polimerasa I de ADN de Treponema, se ha estudiado ampliamente debido a la poca homología de la enzima con las ADN polimerasas I de otros microorganismos, y a dos de sus características distintivas: la presencia de una región que codifica un gran contenido de cisteína y la presencia de cuatro inserciones únicas en el gen (20). Este gen se ha utilizado ampliamente en la fase preliminar de subtipificación molecular, análisis muy relevante, ya que permite conocer la diversidad de subtipos circulantes y determinar los cambios en la prevalencia de las cepas a lo largo del tiempo $(32,33)$. El gen de la polimerasa se ha usado preferentemente para detectar casos sospechosos de sífilis (2).
En otros estudios, se ha planteado que la amplificación del gen $16 S A D N r$ requiere una etapa de transferencia con el método de Southern para garantizar la especificidad, debido a la estrecha relación entre las secuencias del $16 S A D N r$ de las especies (31).

En un estudio piloto, Pinilla, et al., determinaron que, mediante la amplificación de una región de $203 \mathrm{pb}$ del $16 S$ ADNr de T. pallidum subespecie pallidum, detectada mediante PCR convencional, la sensibilidad fue diez veces menor que la obtenida con el gen polA (3,28 ng) para la detección del ADN de la espiroqueta (20). En cuanto a la sensibilidad reportada para los genes $16 S$ ADNry polA, se observó un aumento de la sensibilidad con cada gen al hacer una segunda etapa de amplificación; sin embargo, se evidenció mayor sensibilidad con el gen $16 S A D N r$ que con el polA, lo cual se asoció al mayor número de copias, las cuales varían de una hasta 15 por genoma. También, se ha registrado la variación en el número de copias de $A D N r$ entre cepas de la misma especie, lo que, en algunos taxones, se correlaciona con su capacidad para reaccionar a condiciones desfavorables de crecimiento (34).

Con el empleo del gen TpN47 en una PCR anidada, se ha llegado a una sensibilidad del orden de 0,032 pg (21), lo que concuerda con los resultados obtenidos en este estudio, ya que se alcanzaron los $0,52 \mathrm{pg}$ amplificando el mismo gen. 
La diferencia en la sensibilidad de la amplificación de los genes también se relacionaría con el hecho de que la eficacia de amplificación de la PCR probablemente refleja la longitud del producto, lo cual indicaría que los fragmentos más pequeños se amplifican con mayor facilidad (35).

En el presente estudio, al amplificar el gen diana $T p N 47$ de T. pallidum, se obtuvo una especificidad de $100 \%$ en las dos etapas de amplificación de la PCR anidada. En otros estudios se han obtenido resultados similares, por ejemplo, Grange, et al., encontraron que la especificidad en la detección del genoma de T. pallidum fue alta $(92-97 \%)$ al usar como gen diana de amplificación el $T p N 47(1)$.

El ADN de T. pallidum se puede detectar en muestras clínicas de suero, sangre completa, líquido amniótico, tejido placentario embebido en parafina, lesiones cutáneas ampollosas y líquido cefalorraquídeo de niños con sífilis congénita. La detección del ADN en sangre completa y suero en estos pacientes parece ser más confiable que en los pacientes adultos, probablemente debido a la concentración relativamente alta de treponemas en la sangre de los primeros (3).

Liu $\mathrm{H}$, et al., reportaron el éxito de la PCR para detectar T. pallidum en muestras clínicas de sangre completa, fracciones de sangre, líquido amniótico, líquido cefalorraquídeo y úlceras del aparato genitourinario (31). La conservación de las muestras también puede afectar los resultados de la PCR; en este sentido, Buffet, et al., encontraron que aquellas muestras de tejido congeladas inmediatamente antes del análisis conservaron el ADN intacto, lo que podría explicar una mejor sensibilidad en los hallazgos (3).

En el presente estudio, se logró amplificar el ADN de T. pallidum en tres tipos de muestra: suero, líquido cefalorraquídeo y sangre de cordón. Además, para obtener resultados óptimos, es necesario utilizar diferentes métodos de conservación y de preparación, según el tipo de muestra (17).

Al comparar los resultados de la PCR con los de las pruebas de serología (VDRL y RPR), Orle, et al., obtuvieron una concordancia de $88 \%$ utilizando una PCR múltiple para la identificación del TPN47 en los 296 pacientes estudiados (30). En el 2001, Bruisten, et al., identificaron el gen bmp de $T$. pallidum y compararon los resultados con los ensayos serológicos TPHA, RPR y FTA-Abs en 364 pacientes mediante una PCR múltiple anidada $y$ encontraron que solo en cuatro pacientes hubo resultados positivos con las pruebas de serología, nueve fueron positivos en la PCR y tres lo fueron tanto en las pruebas de serología como en la PCR, con una concordancia de $96 \%$ (36).

En el presente estudio, se obtuvo una concordancia del $70 \%$ en 20 muestras analizadas mediante PCR anidada y pruebas serológicas (VDRL, RPR y TPPA); de estas 20, 11 (55\%) eran muestras clínicas con resultados positivos en ambas técnicas y tres $(15 \%)$ eran negativas.

Por su parte, Leslie, et al., encontraron una concordancia de $95 \%$ entre la PCR en tiempo real y las pruebas serológicas RPR, TPPA y EIA; en 14 de 301 pacientes, los resultados de la PCR en tiempo real (positivos) discreparon de los obtenidos mediante serología (negativos) y, en todos los pacientes, el umbral de detección presentó valores cercanos al límite (37).

En el presente estudio, también se registraron resultados discordantes en seis $(30 \%)$ muestras procesadas mediante las dos técnicas: una (5\%) muestra fue positiva con la PCR anidada y negativa con serología, y cinco (25\%) fueron positivas en la serología y negativas en la PCR anidada, lo cual podría explicarse por la detección de niveles bajos de $T$. pallidum o por representar resultados falsos positivos debido a la contaminación del ensayo de bajo nivel.

Por otra parte, la explicación más probable para el hallazgo de pacientes negativos en la PCR pero positivos en la serología, sería que el tiempo o el sitio de muestreo no fueron los adecuados (38), como se evidenció en el estudio de Casal, et al. (2), quienes plantearon que, en los estudios que utilizan diferentes genes diana y diversos métodos serológicos, se logra una buena correlación entre la PCR y las pruebas serológicas (entre 88 y $96 \%$ ).

La disminución del porcentaje de concordancia en el presente estudio sugeriría que los pacientes tenían una infección reciente, aunque no se excluyen las posibilidades de una reacción serológica inespecífica, un título bajo de anticuerpos o una concentración de ADN indetectable mediante la PCR (2).

Al comparar los resultados de la PCR convencional y de la PCR anidada, se evidenció que el número de muestras positivas aumentó considerablemente con esta última, lo cual evidencia que este método efectivamente aumentó la sensibilidad en la detección, pues se obtuvo un mayor número de copias del fragmento amplificado. Sin embargo, no se debe obviar el hecho de que una de las desventajas de 
esta PCR con respecto a la convencional, es que requiere más tiempo y materiales, y que el riesgo de contaminación es mayor, lo cual se puede evitar siguiendo las normas preventivas de contaminación para la PCR $(37,39)$.

Por último, se puede concluir que el gen $T p N 47$ es un blanco molecular prometedor y que la técnica propuesta es una alternativa diagnóstica y una herramienta valiosa que puede contribuir al control de la sífilis materna, y al diagnóstico y la vigilancia epidemiológica de la sífilis congénita. Asimismo, puede afirmarse que, si bien con la PCR cuantitativa podría lograrse una mejor sensibilidad, su uso requiere equipos más costosos y sofisticados, así como personal de laboratorio más especializado, por lo cual se restringiría a los laboratorios de referencia.

La implementación a corto plazo de la PCR anidada en los laboratorios clínicos especializados y a mediano plazo en los laboratorios de rutina en países en desarrollo, permitiría la detección temprana de la infección en neonatos y en mujeres gestantes infectadas para garantizar un tratamiento oportuno.

\section{Agradecimientos}

A Yolanda Cifuentes de la Universidad Nacional de Colombia, a los hospitales de tercer nivel de Bogotá y al Hemocentro Distrital, por su contribución en el muestreo realizado. Al Departamento de Inmunopatología de la Sífilis de la Universidad de Washington, Seattle, EE.UU., por suministrar el control positivo para los ensayos.

\section{Conflicto de intereses}

Los autores declaran no tener conflicto de intereses.

\section{Financiación}

Los recursos para la realización de este proyecto fueron suministrados por la Universidad Colegio Mayor de Cundinamarca, por medio de la Convocatoria Interna de Investigaciones 2016-2017.

\section{Referencias}

1. Grange P, Gressier L, Dion P, Farhi D, Benhaddou N, Gerhardt P, et al. Evaluation of a PCR test for detection of Treponema pallidum in swabs and blood. J Clin Microbiol. 2012;50:546-52. https://doi.org/10.1128/JCM.00702-11

2. Casal D, Silva O, Costa I, Araújo C, Corvelo C. Molecular detection of Treponema pallidum sp. pallidum in blood samples of VDRL-seroreactive women with lethal pregnancy outcomes: A retrospective observational study in northern Brazil. Rev Soc Bras Med Trop. 2011;44:451-6. https://doi. org/10.1590/S0037-86822011005000047

3. Buffet M, Grange P, Gerhardt P, Carlotti A, Calvez $\mathbf{V}$, Bianchi $\mathbf{A}$, et al. Diagnosing Treponema pallidum in secondary syphilis by PCR and immunohistochemistry. $J$ Invest Dermatol. 2007;127:2345-50. https://doi.org/10.1038/ sj.jid.5700888

4. De la Hoz F, Martínez M, Pacheco O, Quijada H, Beltrán M, Ramírez C. Protocolo de vigilancia en salud pública. Sífilis gestacional y sífilis congénita. Bogotá: Instituto Nacional de Salud; 2015. p. 2-3.

5. Valderrama J, Zacarías F, Mazin R. Sífilis materna y sífilis congénita en América Latina: un problema grave de solución sencilla. Rev Panam Salud Pública. 2004;16:2117. https://doi.org/10.1590/S1020-49892004000900012

6. Casas-P RL, Rodríguez M, Rivas J. Sífilis y embarazo: ¿cómo diagnosticar y tratar oportunamente? Rev Colomb Obstet Ginecol. 2009;60:49-56.

7. Organización Panamericana de la Salud. Guía clínica para la eliminación de la transmisión materno-infantil del VIH y de la sífilis congénita en América Latina y el Caribe. Washington, D.C.: OPS; 2009.

8. Díaz LA. Sífilis gestacional: un problema de salud pública. Rev Fac Med. 2011;59:163-5.

9. Cruz AR. Situación de la sífilis gestacional y congénita en Colombia, un desafío al Sistema General de Seguridad Social en Salud. Rev Colomb Obstet Ginecol. 2012;63: 308-11.

10. Cifuentes $\mathbf{M}$, Ojeda $\mathbf{C}$. Sífilis congénita en el Instituto Materno Infantil-Hospital La Victoria, Bogotá. Rev Salud Pública. 2013;15:434-45.

11. Herring A, Ballard R, Mabey D, Peeling R. Evaluation of rapid diagnostic tests: Syphilis. Nat Rev Microbiol. 2006;4 (Suppl.):S33-40. https://doi.org/10.1038/nrmicro1563

12. Luu M, Ham C, Kamb M, Caffe S, Hoover K, Pérez F. Syphilis testing in antenatal care: Policies and practices among laboratories in the Americas. Int J Gynecol Obstet. 2015;130(Suppl.1):S37-42. https://doi.org/10.1016/j.ijgo. 2015.04.011

13. Martin I, Weiming G, Tsang R. Macrolide resistance and molecular types of Treponema pallidum causing primary syphilis in Shanghai, China. Clin Infect Dis. 2009;49:51521. https://doi.org/10.1086/600878

14. Ham D, Lin C, Newman L, Wijesooriya N, Kamb M. Improving global estimates of syphilis in pregnancy by diagnostic test type: A systematic review and meta-analysis. Int J Gynecol Obstet. 2015;130(Suppl.1):S10-4. https://doi. org/10.1016/j.ijgo.2015.04.012

15. Singh A, Levett P, Fonseca K, Jayaraman G, Lee B. Canadian Public Health Laboratory Network laboratory guidelines for congenital syphilis and syphilis screening in pregnant women in Canada. Canad $\mathrm{J}$ Infect Dis Med Microbiol. 2015;26(Suppl.A):23A-8. https://doi.org/10.1155/ 2015/589085

16. Martin I, Tsang R, Sutherland K, Tilley P, Read R, Anderson B, et al. Molecular characterization of syphilis in patients in Canada: Azithromycin resistance and detection of Treponema pallidum DNA in whole-blood samples versus ulcerative swabs. J Clin Microbiol. 2009;47:1668-73. https:// doi.org/10.1128/JCM.02392-08

17. Heymans R, Helm J, Vries C, Fennema A, Coutinho A, Bruisten M. Clinical value of Treponema pallidum real-time PCR for diagnosis of syphilis. J Clin Microbiol. 2010;48:497502. https://doi.org/10.1128/JCM.00720-09 
18. Sampedro A, Martínez LA, Teatino PM, RodríguezGranger J. Diagnosis of congenital infection. Enferm Infecc Microbiol Clin. 2011;29:15-20. https://doi.org/10.1016/S0213 $-005 \times(11) 70039-8$

19. Cejková D, Zobaníková $\mathbf{M}$, Chen L, Pospíšilová $\mathbf{P}$, Strouhal M, Qin X, et al. Whole genome sequences of three Treponema pallidum ssp. pertenue strains: Yaws and syphilis treponemes differ in less than $0.2 \%$ of the genome sequence. PLoS Negl Trop Dis. 2012;6:e1471. https://doi. org/10.1371/journal.pntd.0001471

20. Promega. Technical Manual, Wizard Genomic DNA Purification $\mathrm{Kit}^{\circledR}$. Fecha de consulta: 5 de septiembre de 2016. Disponible en: https://www.promega.com/ / media/files/resources/protocols/technical\%20manuals/0/ wizard\%20genomic\%20dna\%20purification\%20kit\%20 protocol.pdf.

21. Pinilla G, Chavarro B, Moreno N, Navarrete J, Muñoz L. Determinación de los genes, $16 S A D N r$, polA y TpN47, en la detección de Treponema pallidum subsp. pallidum para el diagnóstico de sífilis congénita. NOVA. 2015;13:17-25.

22. QIAGEN. QIAamp DNA Mini Kit ${ }^{\circledR}$ and QIAamp DNA Blood Mini $\mathrm{Kit}^{\circledR}$ Handbook 2013. Fecha de consulta: 15 de marzo de 2015. Disponible en: http://emerald.tufts.edu/ mcourt01/ Documents/QIAGEN_protocol.pdf.

23. Macrogen. Normal Automatic Sequencing. Fecha de consulta: 10 de octubre de 2015. Disponible en: http://www. macrogen.com/download/Standard_Seq_Brochure.pdf.

24. Thermo Fisher. VDRL Test $\mathrm{Kit}^{\circledR}$. Fecha de consulta: 2 de febrero de 2015. Disponible en: http://tools.thermofisher. com/content/sfs/manuals/X4988B-ES.pdf.

25. BioKit. Rapid test for the qualitative and quantitative detection of syphilis in serum or plasma. Fecha de consulta: 2 de febrero de 2015. Disponible en: http://docplayer. es/35836985-Rpr-reditest-rapid-test-for-the-qualitative-andquantitative-detection-of-syphilis-in-serum-or-plasma.html.

26. Fujirebio T. Serodia-TPPA. Fecha de consulta: 22 de marzo de 2015. Disponible en: http://www.fdi.com/documents/ products/inserts/PROOF\%20POLLOCK\%20Serodia_TP_ PA_Sheet\%20020912.pdf.

27. Chowdhary N, Rani K, Mukunda K, Kiran K. Early detection of congenital syphilis. J Indian Soc Pedod Prev Dent. 2014;32:333-7. https://doi.org/10.4103/0970-4388.140969

28. Ramos JM, León $R$, Andreu M, de las Parras ER, Rodríguez-Díaz JC, Esteban Á, et al. Serological study of Trypanosoma cruzi, Strongyloides stercoralis, HIV, human $\mathrm{T}$ cell lymphotropic virus (HTLV) and syphilis infections in asymptomatic Latin American immigrants in Spain. Trans R Soc Trop Med Hyg. 2015;109:447-53. https://doi. org/10.1093/trstmh/trv043

29. Gayet-Ageron A, Combescure C, Lautenschlager S, Ninet B, Perneger TV. Comparison of diagnostic accuracy of PCR targeting the 47-kilodalton protein membrane gene of Treponema pallidum and PCR targeting the DNA polymerase I gene: Systematic review and meta-analysis. J Clin Microbiol. 2015;53:3522-9. https://doi.org/10.1128/ JCM.01619-15

30. Noda A, Blanco O, Correa C, Pérez L, Kourí V, Rodríguez I. Etiology of genital ulcer disease in male patients attending a sexually transmitted diseases clinic: First assessment in Cuba. Sex Transm Dis. 2016;43:494-7. https://doi.org/10. 1097/OLQ.0000000000000470

31. Castro R, Águas MJ, Batista T, Araújo C, Mansinho K, Pereira F da L. Detection of Treponema pallidum sp. pallidum DNA in cerebrospinal fluid (CSF) by two PCR techniques. J Clin Lab Anal. 2016;30:628-32. https://doi. org $/ 10.1002 /$ jcla.21913

32. Liu H, Rodes B, Chen C-Y, Steiner B. New tests for syphilis: Rational design of a PCR method for detection of Treponema pallidum in clinical specimens using unique regions of the DNA polymerase I gene. J Clin Microbiol. 2001;39:1941-6. https://doi.org/10.1128/JCM.39.5.1941-1946.2001

33. Pope V, Fox K, Liu H, Marfin A, Leone P, Seña C, et al. Molecular subtyping of Treponema pallidum from North and South Carolina. J Clin Microbiol. 2005;43:3743-6. https:// doi.org/10.1128/JCM.43.8.3743-3746.2005

34. Castro R, Prieto E, Aguas M, Manata M, Botas J, Martins P. Molecular subtyping of Treponema pallidum subsp. pallidum in Lisbon, Portugal. J Clin Microbiol. 2009;47:25102. https://doi.org/10.1128/JCM.00287-08

35. Větrovský T, Baldrian P. The variability of the $16 \mathrm{~S}$ rRNA gene in bacterial genomes and its consequences for bacterial community analyses. PLoS One. 2013;8:e57923.

36. Grillová L, Pětrošová H, Mikalová L, Strnadel R, Dastychová E, Kuklová I, et al. Molecular typing of Treponema pallidum in the Czech Republic during 2011 to 2013: Increased prevalence of identified genotypes and of isolates with macrolide resistance. $\mathrm{J}$ Clin Microbiol. 2014;52:3693-700. https://doi.org/10.1128/JCM.01292-14

37. Leslie E, Azzato F, Karapanagiotidis T, Leydon J, Fyfe J. Development of a real-time PCR assay to detect Treponema pallidum in clinical specimens and assessment of the assay's performance by comparison with serological testing. J Clin Microbiol. 2007;45:93-6. https://doi.org/10. 1128/JCM.01578-06

38. Bruisten M, Cairo I, Fennema H, Pijl A, Buimer M, Peerbooms G, et al. Diagnosing genital ulcer disease in a clinic for sexually transmitted diseases in Amsterdam, The Netherlands. J Clin Microbiol. 2001;39:601-5. https://doi. org/10.1128/JCM.39.2.601-605.2001

39. Mendoza N, Jaramillo C, Guhl F, Padilla J, Rentería M. Diagnóstico de malaria por el método de la PCR anidada. Biomédica. 2001;21:320-7. https://doi.org/10.7705/ biomedica.v21i4.1124 